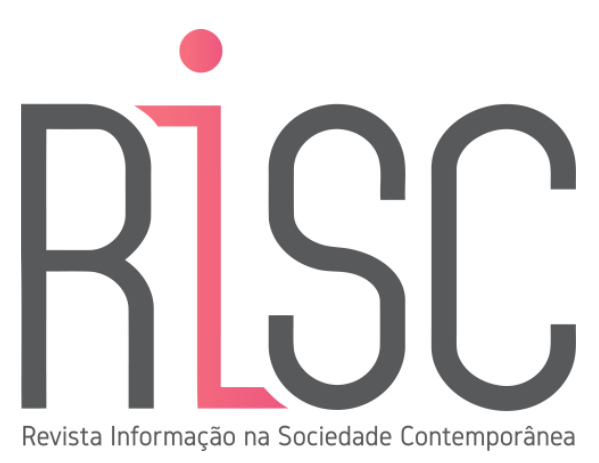

\title{
APRESENTAÇÃO DOSSIER IV CONSÓRCIO MESTRAL E DOUTORAL DA REDE GESTÃO DA INFORMAÇÃO E DO CONHECIMENTO (REDE GIC)
}

\author{
Andrea Vasconcelos Carvalho \\ Doutora em Sistemas de Informação e Documentação \\ Universidade Federal do Rio Grande do Norte, Natal, RN, Brasil \\ https://orcid.org/0000-0001-6763-3716 E-mail: andreavascarvalho@gmail.com
}

É com grande alegria que apresento esta edição especial da Revista Informação na Sociedade Contemporânea dedicada à publicação de trabalhos inicialmente expostos no IV Consórcio Mestral e Doutoral da Rede de Gestão da Informação e do Conhecimento (Rede GIC). Esse evento que tive a oportunidade de coordenar concomitantemente com o II Seminário Nacional de Gestão da Informação e do Conhecimento (II SNGIC) e com a II Reunião dos Grupos de Pesquisa da Rede GIC foi realizado no formato on-line no período de 2 a 4 de setembro de 2020. Nesses dias, reuniram-se professores, estudantes de graduação e de pós-graduação e profissionais interessados na Gestão da Informação e do Conhecimento, a partir da perspectiva da Ciência da Informação e de áreas afins.

No âmbito do IV Consórcio Mestral e Doutoral, mestrandos e doutorandos vinculados as 14 universidades signatárias da Rede GIC (UFSC, UFPR, UFRGS, UEL, UDESC, UFRN, UFPB, UFV, UFG, UNIRIO, UNB, UFPE, UFMG e UFAM) puderam participar de bancas informais, nas quais, mediante uma interlocução qualificada, pesquisadores experientes ofereceram 
contribuições teórico-metodológicas para as pesquisas analisadas, buscando fomentar o aprimoramento das dissertações e teses em andamento sobre a gestão da informação e do conhecimento no país.

A submissão das pesquisas em andamento para apresentação em consórcios, assim como para publicação em periódicos científicos são excelentes oportunidades de aperfeiçoamento de tais pesquisas e, ademais, contribuem para aprimorar a formação dos pós-graduandos e das produções decorrentes de suas investigações. A colaboração de examinadores e avaliadores com distintas formações e distintos repertórios teóricometodológicos contribuem para ampliar e/ou aprofundar a perspectiva adotada na pesquisa em andamento, complementando o trabalho dos orientadores na formação dos novos pesquisadores. Os artigos publicados nesta edição são, pois, uma pequena amostra das pesquisas decorrentes de tal processo.

Embora o IV Consórcio Mestral e Doutoral tenha contado com a exposição de pesquisas em andamento em programas de pós-graduação de distintas instituições vinculadas à Rede GIC, todos os trabalhos aprovados para a composição desta edição da RISC estão sendo desenvolvidos no Programa de Pós-graduação em Gestão da Informação da Universidade Federal do Paraná.

O primeiro artigo tem por título "Necessidade de Informação dos Gestores da Secretaria de Estado da Educação do Estado do Paraná" e pretende contribuir para melhorar a compreensão das necessidades informacionais relacionadas ao processo de tomada de decisão dos gestores, bem como para verificar a eficácia do sistema de informação utilizado para atender a tais necessidades. Este trabalho resulta da dissertação que está sendo desenvolvida por Mires Mendes Carvalho com a orientação da professora Paula Carina de Araújo.

O segundo artigo objetiva analisar as causas para a devolução de recursos recebidos via convênios entre as universidades públicas do Paraná e a Fundação Araucária com vistas a subsidiar a apresentação de soluções que possam minimizar o problema. Com o título "Gestão da informação de convênios entre universidades e fundações de apoio à pesquisa", trata-se de uma produção decorrente da pesquisa de mestrado que está sendo desenvolvida por Edilaine de Azevedo Vieira com a orientação da professora Taiane Ritta Coelho. 
Dando continuidade, temos o artigo "A participação cidadã na perspectiva de uma cidade inteligente: um estudo de caso sobre a plataforma "Fala Curitiba", de autoria da mestranda Andrea Cristina Lima Duarte Ferreira em co-autoria com sua orientadora professora Taiane Ritta Coelho. Esta pesquisa objetiva analisar o impacto da participação cidadã na escolha das prioridades orçamentárias mediante o uso de plataforma de participação on line empregada pela Prefeitura Municipal de Curitiba.

Na sequência, aborda-se um fenômeno recorrente na história da humanidade, mas que tem centralidade e desperta especial interesse no cenário atual: as fake news. "O Fluxo Informacional de Fake News baseadas em denúncias falsas para a destruição da vida privada e pública de cidadãos" é uma produção do mestrando Álvaro Maximiliano Pino Coviello e de seu orientador, o professor Rodrigo Eduardo Botelho Francisco. Os autores objetivam caracterizar o fluxo informacional em dois casos de fake news baseadas em denúncias falsas para a destruição da vida pública e privada de cidadãos.

O quinto texto foi produzido pelo mestrando André Luiz Gomes em parceria com sua orientadora, a professora Taiane Ritta Coelho, e se intitula "A influência da inteligência de mercado no planejamento de uma cidade inteligente". Esta pesquisa busca analisar a influência da inteligência de mercado no planejamento de uma cidade inteligente, potencializando o desenvolvimento empresarial de um território.

Por fim, temos o artigo intitulado "Proposta de um modelo de visualização de dados: mensuração do impacto social da extensão do ensino superior sob à ótica de Campus Inteligente", de autoria de Rafael Ferreira dos Santos e de Taiane Ritta Coelho. Esta pesquisa objetiva propor uma ferramenta de visualização de dados que evidencie o impacto social da extensão de uma universidade de Curitiba, considerando os Objetivos do Desenvolvimento Sustentável.

Diante do exposto, percebe-se que a gestão da informação e do conhecimento está sendo pesquisada em âmbitos que transcendem consideravelmente o tradicional ambiente empresarial, revelando a amplitude dos campos de aplicação da gestão da informação, da gestão do conhecimento e da inteligência competitiva e da multiplicidade de perspectivas sob as quais esses processos podem ser investigados. 
Revela-se, assim, a contribuição da temática para o aprimoramento da gestão pública, para a ampliação da cidadania e para o desenvolvimento e consolidação das cidades inteligentes, por exemplo.

Deste modo, a leitura desta edição, em que se apresentam pesquisas em seus estágios iniciais, é uma oportunidade ímpar de conhecer o que se está investigando no âmbito da gestão da informação e do conhecimento e como a temática está avançando no país, quais temas estão despertando o interesse, que procedimentos metodológicos estão sendo adotados, além da oportunidade de entrar em contato com temas e pesquisadores novos, ou seja, é uma oportunidade de conhecer um pouco do que vem pela frente na temática da gestão da informação e do conhecimento no Brasil.

Por tudo isso, considero esta edição uma iniciativa louvável e parabenizo a editora e os autores envolvidos. Espero que este número seja amplamente divulgado e acessado e que sirva de inspiração para outros semelhantes.

Boa leitura a todos! 